\title{
Calculating Consequences of Road Accidents for Public Administering and Strategic Management of Road Transport
}

\author{
Taras GURZHII, Anna GURZHII, Victor TIMASHOV, Olena ZAPOTOTSKA and \\ Oleh OLIINYK
}

Kyiv National University of Trade and Economics, Kyiv, Ukraine

Correspondence should be addressed to: Taras GURZHII; nosterlex@gmail.com

Received date:10 February 2020; Accepted date:23 February 2021; published date: 9 September 2021

Academic Editor: Elena A. Pavlova

Copyright (C) 2021. Taras GURZHII, Anna GURZHII, Victor TIMASHOV, Olena ZAPOTOTSKA and Oleh OLIINYK. Distributed under Creative Commons Attribution 4.0 International CC-BY 4.0

\begin{abstract}
The article deals with the economic aspect of motor traffic safety on roadways. Relevant problems on calculating economic losses related to road accidents are outlined. The importance of accurate determining of social and economic parameters of motor road accidents has been emphasized on. It has been also stressed that only reliable statistics data can be objective instrument for estimation the Motor Traffic Safety (hereinafter MTS) guarantee system effectiveness, establishment of its functioning regulation, and formulation of realistic concept of its development. In many countries of the world the national systems for collection, systematization and generalization of motor transport safety information have been recently characterized by insufficient accuracy and inefficiency ways. The analysis of the main MTS indicators has been performed according to outdated methods. For decades in a row the condition of MTS has been assessed by narrow range of parameters that are unable to represent comprehensive picture of the socio-economic aspect of motor transport safety. In its turn it causes the poorness of the original statistical material and the imperfection of the concepts, plans and programs of sectoral development having been worked out on its basis. Taking the above mentioned into consideration, it is obvious that the article contains analysis of modern methods for calculating economic losses caused by road accident, as well as formulation of a set of recommendations for their use in public administering and strategic management on motor transport safety.
\end{abstract}

Keywords: Road Safety, Economy, Accident, Direct and Indirect Losses, Material Damage, Cost Structure.

Cite this Article as: Taras GURZHII, Anna GURZHII, Victor TIMASHOV, Olena ZAPOTOTSKA and Oleh OLIINYK (2021), "Calculating Consequences of Road Accidents for Public Administering and Strategic Management of Road Transport ", Journal of Administrative Sciences and Technology, Vol. 2021 (2021), Article ID 644540, DOI: 10.5171/2021.644540 


\section{Introduction}

Strict determined conditions of macroeconomic indicators for traffic regulation level special importance acquires "cost" aspect of its safety. Exclusively on the clear definition basis of amount of material damage (i. e. notional value) from road accidents one can judge the profitability of certain preventive measures and, in general, the effectiveness of the corresponding direction of state policy. Compulsory guarantee of the completeness and objectivity of calculating the economic consequences of the road accidents are the correct determination of their structure. In addition to the obvious losses (damage to vehicles, cargo, road infrastructure, payment for treatment and medical rehabilitation of the victims, etc.) almost every accident causes a number of incidental and consequential costs, which in their totality have a significant impact on the state of the economy (both local and national). Without taking these costs into account it is very difficult to find out the real economic scale of an accident, to identify priority areas for accident prevention, and to evaluate the profitability of road safety measures and programs.

Having grounded on the mentioned above, herewith should be confirmed that a number of "related" international organizations and foreign scientific-research institutions have conducted series of studies over the last decade aimed at establishing comprehensive list of the harmful (firstly, from economical point of view) consequences of an accident. Based on their generalization, we can distinguish the following components of economic damage from road accident: damage to property; losses related to the death of accident participants; losses related to injury of road accident participants; traffic congestion losses; administrative and legal expenses.

* It goes about people died in hospital within 30 days from the date of the accident.

\section{Estimating the cost of human causalities: the issues of methodology}

Losses related to the death of road users in traffic accidents. Beginning from the 1990's of the $20^{\text {th }}$ century, a series of specialized studies were conducted by US and Western European experts to determine the economic impact of road mortality. By the information of Blincoe, Seay and Zaloshnja (2002), the US Department of Transportation released data that estimated the death of one road user costs $\$ 957,787$. This amount includes: first extra medical aid costs - \$ 833; outpatient treatment costs* $\$ 22,095$; loss from termination of professional activity of a person - \$ 595,358; family loss (calculated basing on the market value of childcare services, persons requiring, housekeeping, etc.) - \$ 191,541 ; insurance payments to the close ones and relatives of the deceased - \$ 37,120 ; vacancy replacement costs (this includes the expense for recruiting new employee, the cost of overtime required to complete unfinished projects, and related administrative costs) - \$ 8,702; court charges and other civil costs - \$102,138.

Using the same methodology (referred to in special literature as RME)** Wijnen (2008) estimated one life lost in Netherlands at $€$ 2.4 million (i. e. about \$ 3.4 million). By Heslett (2006), in Great Britain the losses related to the death of road users reaches $E$ 1.4 million. According to Giles (2010), in Australis such losses are about 2.25 million Australian Dollars (approx. \$ 2.0 million). The discrepancy between these indicators and the USA data is explained by the later terms of conducting relevant socioeconomic studies (obviously, the increase in the amount of losses was significantly influenced by the general inflationary processes) as well as by the introduction of additional criteria for estimation of losses from lethal accidents, such as: age, costs for psychological help to relatives, etc.

\footnotetext{
** of Eng. "Real Money Estimate" calculation of real money value.
} 
It should be noted that many European countries (in particular, Italy, Norway, France, Sweden) use fundamentally different method of taxing the fatal accident, which is based on an assessment of society's willingness to pay for the reduction of risks to life. The mechanism of this technique (commonly known as "Willingness to pay" (WTP)) is as follows. Through a series of sociological surveys, it is to be figured out what amount of money the average citizen of the country is willing to pay in theory to reduce the risk of death in the road accident as a certain amount (let's say, $\mathrm{n} \%$ ). Multiplying the corresponding amount by the number of able-bodied populations, we get socially determined "price" of reducing road traffic mortality by $n \%$. Since the percentage reduction in mortality is just the prevention of a certain number of accidents, it is easy to determine the "weighted average cost" of individual's life, based on available data. For this reason, it is just enough to divide the estimated cost of reducing the risk by the number of deaths to be avoided (Gurzhii, 2018).

As Beckmann (2007) admitted, the WTP methodology has gained wide spreading within advanced economies countries and relatively high standards of living, which has led to the willingness of their citizens to donate large sums of money for their own safety. Taking this into account, the cost of human life calculated by the method of "Willingness to pay", significantly (at least twice) exceeds the amount of direct economic losses from lethal accidents. In the research study of Rodney (2018) are shown different WTP-based estimations, according to which the cost of human losses caused by road accidents vary from 6 to 11.3 million Euros (approx. 8.5, 12.7 and 16 million USD).

Both of the above-mentioned methods (RME and WTP) have certain advantages and disadvantages. The first is based on objective figures, but does not take into account the aspect of road mortality such as "pain and suffering". Sometimes this leads to the paradoxical conclusion, for example, that the cost of human life interrupted by a road accident may be less than the damage caused by large-scale traffic congestion. The second is devoid of such a flaw, but has a hypothetical essence: it is based not on facts, but only on the intentions (moreover, unconfirmed by practice) of ordinary citizens.

Nevertheless, from the point of view of domestic socio-economic realities, the WTP technique seems more promising. First, in all its conventions, it gives a fairly clear idea of the socially-determined "price" of a person's life (road user). Second, it has been sufficiently tested by European practice and, admittedly, has proven itself well in formulating a number of sectoral strategies. Third, unlike RME methods, the results of which depend on the specifics of national systems of loss calculation (and they are different in each country), WTP methods are characterized by great versatility. Fourth, the WTP technique carries on positive psychological message: it determines the cost of a saved life, while the RME method calculates the cost of death. On the whole, the "Willingness to pay" method has numerous advantages, in particular that it is compact, cheap, relatively simple, and therefore it's more convenient for immediate implementation;

Losses related to injury to road accident participants. According to statistics, one of the most common consequences of accidents is injuries to road users: pedestrians (up to $40 \%$ of the total number of injured), drivers (30\%), passengers (15\%), cyclists $(10 \%)$, etc. One in five accidents caused by a road accident, results in permanent disability, one in ten leads to disability of the victim.

The nature and severity of these injuries varies widely. The greater bulk of them are bruise, hematomas, concussions (70\%), damage to bones, tendons and joints (12\%), traumatic brain injuries (9\%), spinal injuries (4\%), visual and hearing loss (3\%). According to the International Classification of Injuries (MAIS), about $90 \%$ of accidents caused by road accidents are related as nongrave (MAIS 1 and MAIS 2 levels), 8\% are mid grave severity traumas (MAIS 3), the remaining $2 \%$ are serious grave traumas (MAIS 4 and MAIS 5). 
Taking into account the high graduation of road injuries, finding out its economic consequences through sociometric techniques (in particular, the WTP technique) it seems very problematic. The vast majority of citizens are not aware of medical classifications for human injury and therefore cannot form a clear opinion about the "price" of reducing correspondent risks (for example, the risk of non-grave trauma, moderate injury, severe trauma, or the like). In this regard, the economic range of road traffic injuries is determined by calculating the cost of the costs incurred. By Thomas, Wozdin, and Mackay (2007) these include: - emergency aid expenses (consisting of the cost of working hours of resuscitation crews, used medicines, fuel, etc.); - costs for outpatient treatment; - expenses for medical rehabilitation; losses from temporary or permanent disability; insurance and social payments; - loss of life expectancy (calculated as the cost of social services related to the performance of lost childcare and household functions); expenses caused by the performance of professional functions of the victim during the period of disability; - court expenses.

Analyzing the structure of these costs, Blincoe, Seay and Zaloshnja (2002) concluded that in USA depending on the severity of the injury, their amount can range from $\$ 170$ (minor injuries: bruises, scratches, minor bleeding) to $\$ 1$ million (injuries that result in permanent loss of essential functions of vital activity: damage to the spine, brain, loss of vital organs, etc.). According to estimates by New Zealand experts, the average "cost" of one traumatic accident in road transport is $\$ 100,000$ (see: The Social Cost of Road Crashes and Injuries, 2019). At the same time Wijnen (2010) estimates corresponding damages on 0.25 million Euros (\$ 0.35 million).

Along with it, none of these amounts can serve as a reliable benchmark for the economic justification of activities (concepts, plans, programs) in a particular country. The output data of those studies is strictly determined by the peculiarities of national economies and their basic parameters, such as: the national currency, the market value of goods and services, household income, etc. Therefore, even in countries with approximately equal level of economic development, the same method of calculation gives quite different results. And what is to be said about leaders and "outsiders" of the world economy: their losses from road injuries differ in several orders of magnitude.

The above-mentioned points to the necessity for the introduction of "own" mechanism in each country for assessing the consequences of an accident - a mechanism that would meet generally accepted world standards and, at the same time, fully take into account the domestic economic realities (price situation, level of social security, medical development, etc.).

\section{Direct and indirect material (non-human) losses related to road accidents.}

Damage to property. According to statistics, up to $95 \%$ of road accidents finish up by more or less serious damage to vehicles, about 15\% by destruction of elements of road infrastructure (pillars, borders, bumpers and other protective structures), more than 5\% by property defilement of pedestrians rights, cyclists, animal chasers; $1,5 \%$ - by damage to valuable, expensive cargo. In addition, some car accidents $(0,1-0,2 \%$ of the total number) cause damage to objects that are not integrated into the road-street system: residential buildings, farm buildings, yards and the like.

Keeping in mind the absolute dominance within the structure of property losses from road accidents, the costs associated with the repair of vehicles (according to various estimates, their share reaches 95-98\%), Burch (2019) finds it inappropriate to calculate the damage caused to other property accurately. In the whole, this approach seems justified. Firstly, the information on the total "cost" of damage to vehicles is sufficient to cover the overall extent of property losses in the road and transport sector. Secondly, the damage caused to the cargo or property (excluding technical means of transportation) by road-traffic users is extremely multidimensional and complex. Therefore, its estimation requires enormous resources, which are not 
comparable to the weight of the specific result.

However, it is not reasonable to reject the idea of calculating losses from road equipment damage. The amount of these losses is rather large, but the calculation procedure is relatively simple (since the respective objects are on the balance sheet of state and communal enterprises, their current price is determined by universal formula, and all expenses for their renovation are clearly recorded in the budget documentation). Although this issue is worthwhile in-depth consideration; in this case the calculation of property damage is supposed to be economically grounded;

According to statistics, up to $95 \%$ of road accidents finish up by more or less serious damage to vehicles, about $15 \%$ - by destruction of elements of road infrastructure (pillars, borders, bumpers and other protective structures), more than $5 \%$ - by property defilement of pedestrians rights, cyclists, animal chasers; $1,5 \%$ - by damage to valuable, expensive cargo. In addition, some car accidents $(0,1-0,2 \%$ of the total number) cause damage to objects that are not integrated into the road-street system: residential buildings, farm buildings, yards and the like.

As Burch (2019) admits, keeping in mind the absolute dominance within the structure of property losses from road accidents, the costs associated with the repair of vehicles (according to various estimates, their share reaches 95-98\%), the vast majority of researchers find it inappropriate to calculate the damage caused to other property accurately. In the whole, this approach seems justified. Firstly, the information on the total "cost" of damage to vehicles is sufficient to cover the overall extent of property losses in the road and transport sector. Secondly, the damage caused to the cargo or property (excluding technical means of transportation) by roadtraffic users is extremely multidimensional and complex. Therefore, its estimation

* The largest traffic congestion in the world was recorded on November 2013 on the streets requires enormous resources, which are not comparable to the weight of the specific result.

However, it is not reasonable to reject the idea of calculating losses from road equipment damage. The amount of these losses is rather large, but the calculation procedure is relatively simple (since the respective objects are on the balance sheet of state and communal enterprises, their current price is determined by universal formula, and all expenses for their renovation are clearly recorded in the budget documentation). Although this issue is worthwhile in-depth consideration; in this case the calculation of property damage is supposed to be economically grounded;

Traffic congestion losses caused by road accidents. A large number of car accidents (especially those occurring in cities) lead to a rapid decline in traffic dynamics and mass congestion of vehicles. Failure of road and street infrastructure, critical damage to vehicles, localization of the accident scene before the arrival of emergency or ambulance vehicles, medical and other services - all this significantly reduces the capacity of the respective sections of roads and streets, disrupts the normal rhythm of traffic flow. As a result, tens, hundreds, or even thousands* of cars are blocked in traffic jams and their passengers are forced to wait for hours to eliminate the effects of a road accident.

In practice, the period of forced downtime results in serious economic losses. Due to constant acceleration of speed, deceleration and the usage of idling of the engine (this is the nature of the movement in conditions of excessive concentration of transport), the wear rates of the main units of the car increase by $10-15 \%$, the average fuel consumption is almost twice. The volumes of exhaust gases and, consequently, their harmful effects on the environment increase proportionally. Drivers and passengers spend free and working hours in traffic jams, which causes a decline in production,

of the Brazilian metropolis of Sao Paulo. Its total length was $309 \mathrm{~km}$, and the number of participants exceeded 4 million people.

Taras GURZHII, Anna GURZHII, Victor TIMASHOV, Olena ZAPOTOTSKA and Oleh OLIINYK, Journal of Administrative Sciences and Technology, DOI: 10.5171/2021.644540 
reduced productivity, and the application of disciplinary sanctions for late work. Long stay in the car traffic jam and related conflicts cause mental fatigue, irritability, stresses, which is not only harmful for the health of road users but it also sometimes serves as a catalyst for further social behavior (accumulated fatigue can may subsequently result in a domestic altercation, eventually break into profession, or even provoke illegal actions). Traffic congestion is often an insurmountable obstacle for medical, ambulance and other emergency vehicles, including those being in a hurry to the traffic accident scene. As a result, the probability of fatalities increases: according to Smith (2009), long (more than 20 minutes) delays in ambulance crews become an indirect cause of the death of $34.3 \%$ of seriously injured road accident participants.

Due to the widespread and multifaceted nature of the damage they cause, traffic jams (especially those occurring at car accidents) have repeatedly been the subject of special economic research. In the course of the latter Garcia (2017) estimated that the total amount of correspondent losses for Western Europe is calculated on the level of about 3.5 billion Euros per year (that is about 150 million Euros per country). Road congestion is thus a major economic problem that needs urgent consideration and resolution on the national state level.

Administrative and legal expenses (costs related to administrative or criminal proceedings). Traffic accident is not just an accident resulting in material damage. It is also a legal fact that "brings to life" a wide range of legal relationships, and causes the launch of a complex legal and procedural mechanism. Depending on the nature of the damage caused, each accident serves as a basis for initiating and considering legal case. This process involves a set of procedural measures and a number of legal documents. It involves statutory entities funded by the state budget (inspectors, investigators, judges, attorneys, etc.). Therefore, legal proceedings always have a certain "price", which includes: a) the cost of working time for judicial and law enforcement personnel spent on the road accident case; b) the cost of the procedural steps taken in the relevant administrative or criminal proceedings; c) the cost of legal services provided to the parties involved (defendant, victim, etc.).

Considering the relative complexity of the correspondent proceedings and the cost of individual procedural actions (registration of the accident or crime scene, technical expertise, etc.), administrative and legal costs occupy prominent place in the structure of the economic consequences of the road accident. According to Downey and Coalman (2004), the preliminary (police) investigation of one road accident "costs" about $\$ 120$, and the trial of the criminal case, taking into account the services of a lawyer is almost \$ 1.3 thousand. The annual expenses involved in implementing the relevant jurisdictions are: 80 million dollars for Australia (Global Status Report on Road Safety, 2015); for the UK it is \$ 55 million (Road Casualties in Great Britain, 2019); for the US - over \$300 million (Jameson, Lesley, and Smith, 2008). Obviously, the amount of this level can significantly affect the profitability of sectoral plans, programs and projects, and therefore should always be taken into account when developing them.

The list of economic consequences of the road accident can be continued. In addition to the above indicated expenses it includes: the cost for fuel and deterioration of vehicles for special purposes (rescue, fire, ambulance ones and the like), for environmental ecological damage from getting of toxic substances into the soil, for the effects of psychological stress caused to road users, for the diseased of fauna objects, and so on. Taken together, they cause a major threat to national interests and civic well-being, which requires road safety to be raised to a higher, overall economic level. The state strategy of traffic safety should be developed and implemented within the framework of economic policy, the main priorities of which are the socio-economic stability of society and state, following the Constitutional rights and freedoms of citizens, legality, and law-abiding of all. 


\section{Conclusions}

Summarizing the analysis of socio-economic characteristics of the road traffic secure, we can affirm the following. Road safety is a complex, multi-faceted phenomenon that has a tremendous impact on the demographic situation and the global economy. The scale of this impact far outweighs the effects of international terrorism, natural disasters or military conflicts. Considering social "dimension" it is comparable to the loss of mankind from the most dangerous diseases: cardiovascular disease, AIDS, pneumonia. Road accidents are the leading cause of death among young people between the age of 15 and 29, and governmental expenses in approximately $3 \%$ of GDP [17, p. 7].

Regarding overwhelming importance of the road safety, global international structures and the world's leading powers include it into the list of major political priorities. Road safety is recognized by them as a key criterion for the efficiency of transport connections, a key to the dynamic development of the economy (in particular, the manufacturing sector), and, at the same time the guarantee of human rights for the protection of life and health (Global Status Report on Road Safety, 2015).

Prioritization of the road traffic secure issues is embodied in the formulation of national strategies and the adoption of longterm targeted programs designed to ensure steady reduction of road accidents and injuries. Each of these programs is the result of complex calculations (estimating, forecasting, calculating), the accuracy of which depends on the completeness and objectivity of information on the socioeconomic parameters of the road safety. It is like in general planning, and the rule here is as follows: the more authentic is the initial data, the higher is the reliability of the corresponding calculations. Therefore, the most developed countries pay the utmost attention to the issues of collecting, processing and organizing information that characterizes key aspects of the road safety: technical, social, economic, etc.
Many countries of the Western Europe, North America, as well as of the Asia-Pacific region use comprehensive informational and analytical systems for assessing the state of the road traffic secure, grounded on modern progressive methods and integrated into a nationwide network of statistic accounting. These systems ensure continuous monitoring of the road accidents; provide comprehensive information on its scope, structure, dynamics, socio-economic implications; guarantee prompt updating of relevant statistics; enable synchronous correlation of data obtained through different channels of national statistics. Their introduction not only improved the accuracy of sectoral planning, but also ensured reaching a new level of reliability, efficiency and effectiveness.

Unfortunately, in many countries (including European) such a system has not yet been established. The analysis of the state of road safety is carried out according to outdated methods. The subjects of statistical report operate in separately and in noncoordinated manner, lacking consistency among their structural units. The depth of analytical "processing" is very far from the required level: for decades in a row, the status of the road traffic secure has been estimated by a narrow range of parameters (mostly the total number of car crashes and their victims) unable to give a comprehensive picture of the socioeconomic aspect of the road safety. This, in its turn, causes poor "output" of statistical array and the neglect of the concepts (plans, programs) of sectoral development grounded on its basis.

In the light of the above mentioned, it is necessary to introduce modern methods that are to allow the calculation of expenses on human life and health, as the basic indicator of the budget estimates of national targeted programs, national and regional development programs. Their arsenal should be continuously enriched, but the procedural mechanisms, on the contrary, should be unified and simplified. Appropriate techniques are to include: a) estimation of direct economic losses (property damage, medical expenses, legal 
expenses, insurance payments, environmental damage, etc.); b) estimation of lost benefits (wages of the victim, GDP per capita); c) the cost of moral and physical suffering; d) estimation of the "willingness to pay" approach (i. e., the amount of money that the average citizen of the country is ready to pay for the risk reduce of the road accidents). The calculations proceeded on this basis should form the foundation of the calculation of the economic part of all national and regional road safety programs, being mandatory criterion at the same time for determining their effectiveness.

\section{References}

- Burch, S. (2019) Road Safety Improvement: Social and Economic Cost, ACC, Pert.

- Blincoe, L. J., Seay, A.G. and Zaloshnja, E. (2002) The Economic Impact of Motor Vehicle Crashes, U.S. Department of Transportation, National Highway Traffic safety Administration, Washington, D.C.

- Wijnen, W. (2008) Road safety and economics in the Netherlands, SWOV, Leidschendam.

- Heslett, Ch. (2006) 'Each road death costs community staggering $1.4 \mathrm{~m}$. (pounds sterling)', Yorkshire Evening Post, Feb. 8.

- Giles, D. (2010) 'One fatal crash costs community \$2.25 million', Sunday Mail, Jan. 17.

- Gurzhii, T. (2018) 'The "Cost of Human Life" as a Basis for Strategic Transport Security Planning. Eastern European Studies: Economics, Education and Law' Proceedings of the International Scientific Conference. Vol. 1, ISBN 978-
619-7125-43-6, 7-8 June 2018, Burgas, Bulgaria.

- Beckmann, J. (2007) Social and economic consequences of road traffic injury in Europe, European Transport Safety Council, Brussels.

- Rodney, W. (2018) Road Safety in World Economy, TSO, London.

- Thomas, P., Wozdin, E. and Mackay, M. (2007) Future Research Directions in Injury Biomechanics and Passive Safety Research, International Research Council on the Biomechanics of Impact, Zurich.

- Blincoe, L.J., Seay, A.G. and Zaloshnja, E. (2002) The Economic Impact of Motor Vehicle Crashes, U.S. Department of Transportation, National Highway Traffic Safety Administration, Washington, D.C..

- The Social Cost of Road Crashes and Injuries. Annual Update (October 2019), N.Z.M.T., Aukland.

- Smith, T. (2009) Emergency medicine and Road Safety, Tailor\&Foster, Leeds.

- Garcia, J. (2017) Las consecuencias económicas de las averías de camino en Europa: el análisis comparative, Estrella, Barcelona.

- Downey, F. and Coalman, M. (2004) Road crash costs in the world, Bureau of Transport Economics, Canberra.

- Reported Road Casualties Great Britain: 2019. Annual Report, TSO, London.

- Jameson, T., Lesley, A. and Smith, J. (2008) Estimating the cost of road crashes, NHTSA, Washington.

- Global Status Report on Road Safety: 2015. Annual Report, World Health Organization, Geneva. 